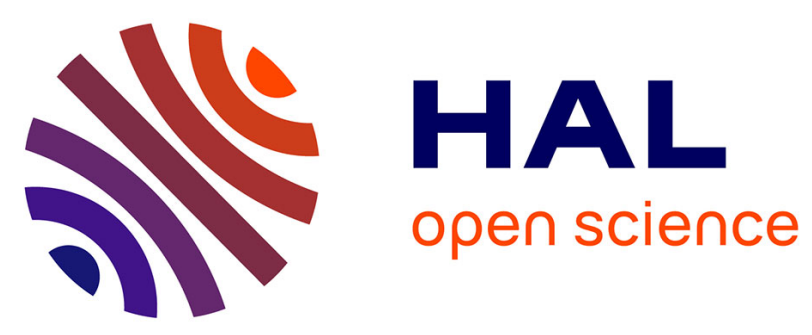

\title{
Colonoscopic screening of first-degree relatives of patients with large adenomas: increased risk of colorectal tumors.
}

Vanessa Cottet, Alexandre Pariente, Bernard Nalet, Jacques Lafon, Chantal Milan, Sylviane Olschwang, Catherine Bonaïti-Pellié, Jean Faivre, Claire Bonithon-Kopp, Angh Group

\section{To cite this version:}

Vanessa Cottet, Alexandre Pariente, Bernard Nalet, Jacques Lafon, Chantal Milan, et al.. Colonoscopic screening of first-degree relatives of patients with large adenomas: increased risk of colorectal tumors.: Adenomas in relatives and colorectal tumor risk. Gastroenterology, 2007, 133 (4), pp.10861092. inserm-00359900

\section{HAL Id: inserm-00359900 https://www.hal.inserm.fr/inserm-00359900}

Submitted on 9 Feb 2009

HAL is a multi-disciplinary open access archive for the deposit and dissemination of scientific research documents, whether they are published or not. The documents may come from teaching and research institutions in France or abroad, or from public or private research centers.
L'archive ouverte pluridisciplinaire HAL, est destinée au dépôt et à la diffusion de documents scientifiques de niveau recherche, publiés ou non, émanant des établissements d'enseignement et de recherche français ou étrangers, des laboratoires publics ou privés. 
COLONOSCOPIC SCREENING OF FIRST-DEGREE RELATIVES

OF PATIENTS WITH LARGE ADENOMAS:

\section{INCREASED RISK OF COLORECTAL TUMOURS}

Vanessa Cottet $^{1}$ MSc, Alexandre Pariente ${ }^{2}$ MD, Bernard Nalet ${ }^{3}$ MD, Jacques Lafon ${ }^{4}$ MD, Chantal Milan ${ }^{1} \mathrm{PhD}$, Sylviane Olschwang MD PhD ${ }^{5}$, Catherine Bonaiti-Pellie ${ }^{6,7} \mathrm{MD} \mathrm{PhD}$, Jean Faivre ${ }^{1}$ MD, Claire Bonithon-Kopp ${ }^{1}$ MD PhD and the ANGH group*

* P Berthelémy (Pau), P Cassan (Vichy), M Glikmanas (Meaux), G Gatineau-Sailliant (Meaux), A Courrier (Metz), D Pillon (Bourg-en-Bresse), JP Michalet (Beaune), JP Latrive (Compiègne), J Guillan (Evreux), A Blanchi (Le Mans), B Bour (Le Mans), T Morin (Tarbes), F Druart (Tarbes), JL Legoux (Orléans), D Labarrière (Orléans), B Naudy (Toulon), D Goldfain (Dreux), A Rotenberg (Dreux), C Bories (Beauvais), J Andrieu (Le Chesnay), J Doll (Le Chesnay), JL Staub (Niort).

1 INSERM U 866, Faculté de Médecine, Dijon, France

2 Centre Hospitalier, Pau, France

3 Centre Hospitalier, Montélimar, France

4 Centre Hospitalier, Aix-en-Provence, France

5 INSERM U 599, Centre Paoli Calmettes, Marseille, France

6 INSERM U 535, Villejuif, F-94817 France

7 Univ Paris-Sud, IFR 69, UMR-S535, Villejuif, F-94817 France 
Correspondence and reprint requests to: Claire Bonithon-Kopp (bonithon@u-bourgogne.fr)

INSERM U866

Faculté de Médecine

BP 87900

21079 Dijon Cedex, FRANCE

tel: 33 3.80.39.33.37 / fax: 33 3.80.66.82.51

Keywords : colorectal tumours, colonoscopy, screening, relatives

Abbreviations used in this paper: OR, odds ratio; CI, confidence intervals, TNM, Tumor Node Metastasis.

\section{Source of support:}

Supported by grants from the French National Society of Gastroenterology, the Ligue Nationale contre le Cancer (France), the Association pour la Recherche sur le Cancer, the Regional Council of Burgundy, the Fondation de France and the French Ministry of Health (PHRC) 
Background \& Aims: The risk of developing colorectal neoplasia is not well established among family members of individuals with large adenomas and screening strategies remain under debate in this population. This study aimed at quantifying the risk of colorectal adenomas and cancers using colonoscopic screening in first-degree relatives of patients with large adenomas.

Methods: This case-control study was performed in 18 endoscopic units of French nonUniversity Hospitals. A colonoscopy was offered to first-degree relatives of 306 index cases with adenomas $\geq 10 \mathrm{~mm}$, if they were alive, aged 40-75 and could be contacted by the index case. Among 674 relatives meeting these criteria, 168 were examined and matched for age, gender, and geographical area with two controls $(n=307)$. Controls were randomly selected from 1362 consecutive patients aged 40-75 having undergone a colonoscopy for minor symptoms.

Results: The overall prevalence of large adenomas was $8.4 \%$ and $4.2 \%$ in relatives and controls, respectively. Odds ratios (OR) associated with a history of large adenomas in relatives were 2.27 (95\% confidence interval [CI]: 1.01-5.09) for cancers or large adenomas and $1.21(95 \% \mathrm{CI}: 0.68-2.15)$ for small adenomas, and $1.56(95 \% \mathrm{CI}: 0.96-2.53)$ for all colorectal neoplasia. The risk of large adenomas and cancers was higher in relatives of index cases younger than 60 years (OR: 3.82; 95\% CI: 0.92-15.87) and when the index case had large distal adenomas (OR, 3.14; 95\% CI: 1.27-7.73).

Conclusion: First-degree relatives of patients with large adenomas are at increased risk of developing colorectal cancers or large adenomas. This result has implications for screening in this high-risk population. 
Colorectal cancer is one of the most common cancers in developed countries, especially in France, where more than 36,000 new cases were diagnosed in $2000{ }^{1}$. Colorectal adenomas are known precursors of most cancers and have high malignancy potential when they are $\geq$ $10 \mathrm{~mm}$ diameter and/or present severe dysplasia and/or villous component ${ }^{2}$. Therefore, detection and removal of colorectal adenomas are presently the best way to reduce cancer incidence and, subsequently, mortality from this cancer ${ }^{3,4}$.

Apart from the two defined genetic syndromes, the Familial Adenomatous Polyposis syndrome and the Hereditary Non Polyposis Colorectal Cancer syndrome, familial clustering of sporadic colorectal cancer is now well recognized. In 2001, a systematic review of 27 epidemiological studies showed that the risk of colorectal cancer increased by 2.25 (95\% confidence interval [CI] from 2.00 to 2.53 ) in first-degree relatives of colorectal cancer cases 5. This finding was confirmed in a more recent meta-analysis of 59 studies, which found a relative risk of 2.24 associated with a history of colorectal cancer in first-degree relatives ${ }^{6}$. The strength of association varied, in particular, according to the number of affected firstdegree relatives (from 1.85 for one relative to 8.52 for at least three affected relatives) and the age of relatives at diagnosis (from 2.18 for relatives $\geq 50$ years to 3.55 for affected relatives $<$ 50 years).

The adenoma-carcinoma sequence suggests that colorectal adenomas and cancers share common environmental and genetic risk factors. However, relatively few epidemiological studies have investigated the risk of developing colorectal neoplasia for first-degree relatives of patients with adenomas. A meta-analysis of nine studies estimated the relative risk of colorectal cancer in relatives of patients with adenomas as $1.99(95 \% \mathrm{CI}, 1.55-2.55){ }^{5}$. Most of these studies used a similar design and compared the frequency of self-reported family history of colorectal cancer among patients with adenomas and either polyp-free controls, or spouse controls, or hospital controls. Thus, the choice of the control group may be 
questionable in some of these studies. Furthermore, information on relatives was not obtained by colonoscopic screening but by interview and is possibly subject to recall biases in the reporting of family histories of colorectal cancers. In addition, these studies could not provide an estimation of the risk of colorectal adenomas, especially high-risk adenomas, in relatives of patients with adenomas. In this targeted population, this latter point is important because the choice of the screening strategy largely depends on the magnitude of the risk of both colorectal adenomas and cancers. As a consequence, screening procedures for relatives of patients with high-risk adenomas are not as well-established as screening strategies for relatives of patients with colorectal cancer.

The GEADE study, a French study about the genetic factors of colorectal adenomas, gave us the opportunity to use an original design to compare the prevalence of colorectal neoplasia detected by endoscopy in first-degree relatives of patients with large adenomas, and in matched endoscopic control patients. Following the findings of a previous work among firstdegree relatives of patients with colorectal cancer ${ }^{7}$, the aim of the present study was to demonstrate and quantify the high risk of both cancers and large adenomas, in first-degree relatives of patients with large adenomas.

\section{Methods}

Study subjects and data collection

The GEADE study is a case-control and family study of patients with high-risk adenomas. The primary aim was to compare the frequency of various susceptibility genes in patients with large adenomas (index cases) and in controls with small adenomas or free of adenomas ${ }^{8}$. A secondary aim based on the family part of the study was to assess the compliance with colonoscopy in first-degree relatives with large adenomas ${ }^{9}$. 
The study was performed in 18 participating gastroenterology units in French nonuniversity hospitals. They were located in small to medium-sized towns throughout the country (six towns were in a large area around Paris called 'Greater Paris area', three in northeast France, two in the South-west, three in the South-east and four in central France). Subjects involved in the present analysis were first-degree relatives of patients with large colorectal adenomas. From September 1995 to March 2000, 306 consecutive patients with a newly- diagnosed adenoma $\geq 10 \mathrm{~mm}$ were enrolled and referred as index cases. Index cases had no previous history of colorectal cancer or other cancer, familial adenomatous polyposis syndrome, established hereditary non-polyposis colorectal cancer and inflammatory bowel diseases. As indicated in Figure 1, 267 patients out of 306 consented to provide information on their family during a face-to-face interview with participating gastroenterologists. Family data included information on all first-degree relatives (parents, siblings and offspring), i.e. demographic and medical characteristics such as name, date of birth and/or age, residence area, vital status, cause and age at death if applicable, history of polyps or cancer. In accordance with French ethical rules, relatives of the patients were not directly contacted by the investigators. During a special consultation, the study was explained to the index cases who were asked to contact their relatives and to pass on an explanatory booklet. The booklet contained an explanatory letter describing the aims of the study and its implementation, general information about colorectal cancer, an informed consent sheet showing the advantages and potential drawbacks of colonoscopy and a health study questionnaire. Information about the genetic part of the study was given, together with a specific informed consent form, tubes for blood sampling and a letter for the customary laboratory used by the relative. Unless they had undergone a colonoscopy during the five preceding years, relatives aged 40-75 were asked to have a colonoscopy with the gastroenterologist of their choice including gastroenterologists practising outside study centres. 
Among 1763 first-degree relatives identified, 674 were alive, aged 40-75 and could be contacted by the index case. One hundred and seventy relatives from 97 families underwent a colonoscopy. Among them, 56 relatives had been examined over the five preceding years, and 114 underwent a screening colonoscopy resulting in an overall proportion of subjects with colonoscopy of $25 \%^{9}$. Reports of endoscopic and, if applicable, histological examinations were obtained for all but 10 relatives, of which eight declared that no lesion was discovered during their colonoscopy and two did not know the results of the colonoscopy. These last two subjects were excluded from the present study. Thus, the case group was composed of 168 first-degree relatives. The colonoscopy was complete in 134 first-degree relatives $(79.8 \%)$, reached the ascending colon in two relatives, whereas no information about the level of colonoscopy was obtained for 32 relatives.

Potential controls were extracted from 4133 consecutive patients aged 40-75 who had undergone a complete colonoscopy in one of the 18 gastroenterology units over a period of one year (or 6 months for 3 centres). Patients with a personal history of colorectal neoplasia $(n=1072)$ or inflammatory bowel disease $(n=104)$, established hereditary non-polyposis colorectal cancer or familial adenomatous polyposis $(n=5)$, and who reported a family history of colorectal cancer and adenomas $(n=696)$ were excluded, as well as those who had undergone a colonoscopy for the following indications: a positive faecal occult blood test $(n=43)$, search for an occult primary tumour $(n=98)$, rectal bleeding $(n=505)$ or severe symptoms such as anaemia $(n=155)$, digestive haemorrhage $(n=33)$, bowel obstruction $(n=28)$, or altered overall condition $(n=32)$. These exclusion criteria aimed at avoiding any over-representation of patients with higher-than-average risk of neoplasia. Finally, 1362 colonoscopic controls met the eligibility criteria. They presented the following indications: abdominal pain $(40.0 \%)$, diarrhoea/constipation $(24.7 \%)$, both abdominal pain and diarrhoea/constipation $(20.0 \%)$ or miscellaneous indications $(15.2 \%)$. Each first-degree 
relative was matched for age, gender and geographical area with two control patients randomly selected from eligible controls. Because only one control could be found for 29 relatives, the control group was composed of 307 patients. Major indications for colonoscopy in selected controls were abdominal pain (43.6\%), diarrhoea/constipation $(22.5 \%)$, both abdominal pain and diarrhoea/constipation $(19.9 \%)$ or miscellaneous indications such as suspected diverticular disease $(14.0 \%)$

For index cases, relatives and matched controls, lesion location was defined as distal (including rectum, rectosigmoïd, sigmoïd, descending colon and splenic flexure) and proximal (including transverse colon, hepatic flexure, ascending colon and caecum).

The research protocol was approved by the ethics committee of Kremlin-Bicêtre Hospital. All index patients and first-degree relatives gave their signed informed consent.

\section{Statistical analysis}

The study design was based on the results of our previous work among first-degree relatives of patients with colorectal cancer $^{7}$. A priori calculations of the sample size were as follows: assuming about 2.5 relatives per index case who would be contacted and a participation rate of $30 \%$ among relatives, the recruitment of 252 index cases provided a statistical power of $80 \%$ to detect an odds ratio (OR) of 2.5 associated with a high risk of both cancers and large adenomas, with 2 controls per case and a prevalence of cancers/large adenomas of $4 \%$ in controls (unilateral test). For added security, we extended the recruitment of index cases to 306 .

A logistic regression analysis was used to compare the prevalence of lesions between relatives and control subjects, and results were expressed as odds ratios (OR) and 95\% CI. Both conditional and unconditional logistic regressions, adjusted for matching variables (age, geographical area and sex), were performed. Because they yielded very close results, we have 
chosen to show results from the unconditional logistic regression only for sake of simplicity. In these analyses, the most severe colonoscopic finding was introduced as an independent variable in several ways. It was considered as a dichotomous variable (cancer or adenomas versus no colorectal neoplasia), a four-class categorical variable (cancer versus large adenomas versus small adenomas versus no colorectal neoplasia), or a three-class categorical variable (cancer or large adenomas versus small adenomas versus no colorectal neoplasia). In addition, stratified logistic regression analyses were carried out according to characteristics of the index case at diagnosis. Given that there may be some degree of correlation between relatives of the same family, main data were reanalyzed by keeping only one relative per family ( $\mathrm{n}=96)$ and matched controls $(\mathrm{n}=174)$. The analysis included all relatives from families with a single member and one randomly selected relative from each family with 2 or more members. All statistical analyses were performed using SAS software (version 9.1; SAS Institute, Cary, North Carolina, USA).

\section{Results}

The median age of first-degree relatives and controls was 53 years and 57 years, respectively. Among the 168 first-degree relatives, there were 12 parents (7.1\%) of the index case, 104 siblings $(61.9 \%)$ and 52 children $(31.0 \%)$. The median age was 66 years for the parents (range 52-74), 61 years for the siblings (range 42-73) and 46 years for the children (range 40-59). As shown in Table 1, there were no significant differences between relatives and controls regarding age, gender and geographical area.

Colonoscopic findings among first-degree relatives and controls are shown in Table 2. Five cancers were observed in relatives (one TNM stage I, one stage II, one stage IV and two cancers with unknown stage) and 3 cancers in controls (one stage I and two stage III cancers). With these new observations in first-degree relatives, one family was found to meet 
Amsterdam criteria (three affected members from two generations, of whom one was under 50 at the diagnosis of colorectal cancer). Among subjects free of colorectal cancer, 33 relatives and 47 controls presented at least one adenoma. Prevalence of adenomas was higher in men than in women in both relatives $(24.0 \%$ versus $16.1 \%)$ and controls $(17.3 \%$ versus $14.9 \%$ ). The prevalence of adenomas also increased with age in both relatives and controls. It was $17.7 \%$ in relatives under 60 and $22.7 \%$ in those over 60 whereas the corresponding figures were $11.0 \%$ and $22.4 \%$ in controls.

Colorectal neoplasia was found in 38 out of 168 relatives $(22.6 \%)$ and in 50 out of 307 controls $(16.3 \%)$. The prevalence of cancers was $3.0 \%$ in relatives and $1 \%$ in controls, and the prevalence of large adenomas was $5.4 \%$ and $3.3 \%$, respectively.

The risk associated with one first-degree relative affected by large adenomas depended on the severity of neoplasia (Table 2). For large adenomas and cancers considered together, the OR was $2.27(95 \% \mathrm{CI}, 1.01-5.09)$. It was 1.21 for small adenoma (95\% CI, 0.68-2.15). The overall risk of colorectal neoplasia was not significantly higher in relatives compared to controls, with an OR of $1.56(95 \% \mathrm{CI}, 0.96-2.53)$. One first-degree relative with large adenomas was not a significant risk factor for either high-risk adenomas (adenomas $\geq 10 \mathrm{~mm}$ and/or villous component and/or severe dysplasia or carcinoma in situ) or multiple adenomas. These results did not change when relatives from a putative HNPCC family after detection of a cancer and their matched controls were excluded.

Exclusion of first-degree relatives with a family history of colorectal cancer $(n=32)$ and of their matched controls $(n=59)$ only had a marginal influence on the overall risk of large adenomas and cancers considered together $(\mathrm{OR}, 2.09,95 \% \mathrm{CI}, 0.86-5.13 ; \mathrm{p}=0.11)$, on the risk of small adenomas (OR, 1.23, 95\% CI, 0.64-2.37, $\mathrm{p}=0.54)$, and on the overall risk of colorectal neoplasia $(\mathrm{OR}=1.57,95 \% \mathrm{CI}, 0.99-2.49, \mathrm{p}=0.11)$. Similarly, the restriction of analysis to a case group composed of only one relative per family $(n=96)$ and to matched 
controls $(n=174)$ one marginally affected risk estimates for both cancers/large adenomas $(O R$, 2.62; 95\% CI, 0.74-9.22; $\mathrm{p}=0.13$ ), small adenomas (OR, 1.12;95\% CI, 0.54-2.31; $\mathrm{p}=0.76$ ), and overall neoplasia (OR, 1.35; 95\% CI, 0.71-2.58; $\mathrm{p}=0.36)$.

As indicated in Table 3, certain characteristics of the index case affected the prevalence of colorectal neoplasia in relatives. The risk of finding large adenomas or cancers in first-degree relatives was higher when their index case was under $60(\mathrm{OR}=3.82 ; 95 \% \mathrm{CI}$, 0.92-15.87; $\mathrm{p}=0.07)$, was male $(\mathrm{OR}=4.01 ; 95 \% \mathrm{CI}, 1.45-11.09 ; \mathrm{p}=0.01)$, presented a large adenoma in the distal colorectum $(\mathrm{OR}=3.14 ; 95 \% \mathrm{CI}, 1.27-7.73 ; \mathrm{p}=0.01)$, or had an advanced adenoma (OR, 2.31; 95\% CI, 0.88-6.04; $\mathrm{p}=0.09)$. For relatives of index cases with distal adenomas, the risk of large adenomas or cancers in the left colorectum was particularly high (OR, 3.22; 95\% CI, 1.20-8.63; $\mathrm{p}=0.02)$. Moreover, relatives presented a higher risk of overall neolasia in the left colorectum $(\mathrm{OR}=2.27 ; 95 \% \mathrm{CI}: 1.12-3.84, \mathrm{p}=0.02)$ than in the right colon (OR, 0.68; 95\% CI, 0.24-1.94; $\mathrm{p}=0.47)$.

\section{Discussion}

In this study, first-degree relatives of patients with large adenomas had an increased risk of both colorectal cancers and large adenomas. Moreover, the strength of the relationship varied according to certain characteristics of the index case. The risk was particularly high if the index case was under 60 at diagnosis of a large adenoma, male, or had a large adenoma in the left colorectum. It should be noted that having a first-degree relative with large adenoma had no significant influence on the overall risk of colorectal neoplasia because of the lack of effect on small adenomas

This study had an original design and, to our knowledge, was the first to prospectively ask first-degree relatives of patients with large colorectal adenomas to undergo a colonoscopy, and to compare endoscopic findings to those observed in a control population. 
This contrasts with previous studies which compared frequency of a family history of colorectal cancer among patients with newly diagnosed adenomas, with that among control ${ }^{12-}$ 17. In these studies, the choice of controls such as spouses or hospital controls is questionable and may lead to an underestimation of the association with family history. Furthermore, they do not allow for any assessment of the risk of adenoma in relatives. Indeed, first-degree relatives may had never undergone a colonoscopy and, even if this had been the case, the study subjects could have been unaware of the endoscopic findings in their relatives. Furthermore, these retrospective studies may be subject to recall biases, because patients with adenomas are more likely than control patients to remember a family history of colorectal cancer. Lastly, in most previous studies, no attempt had been made to validate a self-reported family history of colorectal cancer, by direct interview of relatives or by review of medical records.

The present study also presented several limitations, suggesting however that our risk estimates were rather conservative. Because of recruitment procedures of relatives of patients with large adenomas, the ideal design could have been to offer a colonoscopy to first-degree relatives of polyp-free patients. Such a design was impossible for ethical and statutory considerations and we chose to include as controls, consecutive patients who had had a colonoscopy for minor symptoms and did not report any family history of colorectal cancer or adenoma. Our choice was guided by several considerations. First, first-degree relatives were generally asymptomatic, and it was preferable to have a control group as close as possible to this population. Second, the exclusion of patients with a family history of colorectal cancer had the advantage of discarding some patients with an unknown family history of colorectal adenomas, a feature probably common in the general population. Although this strategy could theoretically lead to an over-estimation of the differences in prevalence of neoplasia between cases and controls, it appeared to be the most appropriate because the family history of 
colorectal cancer was the sole indication or one of the indications for colonoscopy in $92 \%$ of these patients. Despite these precautions, a history of large adenomas in first-degree relatives was probably unknown to certain controls, which in turn led to an under-estimation of the association with the risk of colorectal neoplasia. Another limitation was linked to the small proportion of first-degree relatives who agreed to participate in the study and underwent a colonoscopy. It is uncertain whether the participating first-degree relatives were truly representative of the 674 eligible first-degree relatives or of all 1763 living and deceased firstdegree relatives. However, we showed in previous research that the compliance of relatives with colonoscopy was only marginally influenced by the characteristics of both relatives and index cases ${ }^{9}$, so that it is unlikely that major selection biases may have affected our study sample. The main determinants of compliance with colonoscopy for first-degree relatives were their young age and place of residence outside of Greater Paris area (both used as matching variables in the present analysis), whereas family history of colorectal cancer had no significant influence on participation rate. Usually, subjects who participate in screening programs are healthier than non participants. Thus, the observed frequency of colorectal neoplasia in relatives may be lower than the actual frequency, possibly resulting in an underestimation of the differences with controls. Another limitation was due to the lack of information about completeness of colonoscopy could be ascertained in $20 \%$ of relatives, generally examined outside study centres. Thus, if the colonoscopy was incomplete in some of these subjects, we cannot exclude attenuation in the relative risk of colorectal neoplasia. Lastly, because of the low participation rate of first-degree relatives, this is a relatively smallsized study with a statistical power of only $75 \%$ to detect an OR of 2.5 associated with the risk of both cancers/large adenomas and a limited power to detect weaker associations between a family history of large adenomas and the risk of colorectal neoplasia. 
Despite these limitations, the findings of the present study showed striking similarities with those obtained in a previous French study, which used a comparable design for firstdegree relatives of patients with colorectal cancer ${ }^{7}$. In this previous study as in the present one, no association was found with the risk of small adenomas (odds ratio of 1.2) whereas the risk of large adenomas was significantly increased by 2.5 in subjects with a family history of colorectal cancer. Eight of the nine studies included in a recent review also found an increased risk for first-degree relatives of colorectal cancer associated with adenoma, with a summary estimate of familial risk at $1.99^{5}$. Only one of these studies examined the risk of colorectal cancer for first-degree relatives according to the size of adenomas in index cases ${ }^{13}$. The comparison of several groups of adenoma patients and polyp-free controls revealed that the relative risk of colorectal cancer for first-degree relatives was higher in relatives of patients with large adenomas than in those with small adenomas (odds ratios of 2.1 and 1.2, respectively). These findings were partially confirmed by a recent study, which showed only a modest and non-significant increase in the risk of colorectal cancer in relatives of patients with small tubular adenomas (odds ratio of 1.26), and a significant increase in relatives of patients with advanced adenomas, i.e. adenomas larger than $10 \mathrm{~mm}$ and/or with villous component or high-grade dysplasia (odds ratio of 1.62$)^{14}$. Thus, despite some variations among studies in the magnitude of familial risk due to differences in study design and populations studied, there now appears to be strong evidence that first-degree relatives of patients with large adenomas are at high risk of developing colorectal neoplasia, whereas it is probably not the case for relatives of patients with small adenomas. This is consistent with epidemiological knowledge about adenomas. Adenomas are very common in the general population as indicated by autopsy studies ${ }^{16,17}$. In a French autopsy study, overall adenoma prevalence was around $28 \%$, increasing from $16 \%$ in the under-64 age group to $33 \%$ in the 65-74 age group and $46 \%$ in the over-74 age group (personal data). If all individuals with a 
history of adenoma in their first-degree relatives were at high risk of colorectal neoplasia, the incidence of colorectal cancer in the general population would probably be higher than it is.

There are some indications that the risk of colorectal neoplasia in relatives might depend on the characteristics of the affected family member. Indeed, this study showed an increased risk of neoplasia, especially of large adenomas and cancers, when the index case was male and younger than 60 years. A link between a younger age at adenoma diagnosis and familial risk of colorectal cancer has previously been reported in a number of studies $10,13,15$ but not in one study ${ }^{14}$, possibly due to a narrower age range concerning adenoma patients. Furthermore, our study suggested that first-degree relatives of patients with a large distal adenoma could be more prone to develop colorectal neoplasia, especially distal large adenomas and cancers, than relatives of patients with proximal adenomas. Also in the study of Lynch et al. ${ }^{14}$, the prevalence of family history of colorectal cancer was slightly higher in patients with distal adenomas than in patients with proximal adenomas. In addition, our previous work performed with a similar design among first-degree relatives of patients with colorectal cancer also revealed an influence of cancer location ${ }^{7}$. In this latter study, relatives of patients with distal cancer were more likely to present high-risk adenomas than relatives of patients with proximal cancer. As in the present study, adenomas were more likely to be located on the left colon when the cancer site was the left colon. Thus, although no firm conclusions could be drawn from existing data, these may suggest some degree of resemblance in tumoral site among family members. This hypothesis needs to be more thoroughly investigated in future studies using appropriate design and sample size.

Thus, there is now evidence that first-degree relatives of patients with large adenomas may need to be screened and monitored as carefully as relatives of patients with colorectal cancer. This may be especially true for relatives when the index case is younger than 60 years, male and had large adenomas in the left colorectum. However, screening recommendations 
for relatives of patients with large adenomas raise some issues. At the individual level, colonoscopy would probably be the most appropriate screening method in these high- risk subjects. According to the most recent French recommendations, individuals with a family history of colon cancer or adenomas diagnosed in first-degree relatives under 60 should be advised to have screening colonoscopy either from the age of 45 years, or 5 years younger than the earliest diagnosis in their family ${ }^{18}$. No well-defined specific recommendation was proposed for individuals with first-degree relatives older than 60 years diagnosed with colorectal cancer because of the small increase in risk. Likewise, American guidelines recommend colonoscopy at 40 years, or 10 years before the index case, for individuals with a strong family history of colorectal cancer or polyps ${ }^{19,20}$. However, from a public health point of view, there is no evidence that such screening strategies may be the most cost-effective if the acceptability of colonoscopy in first-degree relatives of patients with large adenomas is as low as in our study (around 20\%). Furthermore, our previous analyses showed a strong intrafamilial correlation of colonoscopic screening acceptance, indicating that a large proportion of families would be completely excluded from screening (around 40\%) ${ }^{9}$. Appropriate strategies need to be developed to improve the acceptability of colonoscopy in affected families. Further studies are needed in order to compare the cost-effectiveness of alternative strategies to colonoscopy, such as faecal occult blood testing with sensitive tests and computed tomographic virtual colonoscopy. 


\section{References}

1. Bouvier AM, Remontet L, Jougla E, Launoy G, Grosclaude P, Buemi A, Tretarre B, Velten M, Dancourt V, Menegoz F, Guizard AV, Mace Lesec'h J, Peng J, Bercelli P, Arveux P, Esteve J, Faivre J. Incidence of gastrointestinal cancers in France. Gastroenterol Clin Biol 2004;28:877-81.

2. Winawer SJ, Zauber AG, Fletcher RH, Stillman JS, O'Brien MJ, Levin B, Smith RA, Lieberman DA, Burt RW, Levin TR, Bond JH, Brooks D, Byers T, Hyman N, Kirk L, Thorson A, Simmang C, Johnson D, Rex DK. Guidelines for colonoscopy surveillance after polypectomy: a consensus update by the US Multi-Society Task Force on Colorectal Cancer and the American Cancer Society. Gastroenterology 2006; $130: 1872-85$

3. Jorgensen OD, Kronborg O, Fenger C. The Funen Adenoma Follow-up Study. Incidence and death from colorectal carcinoma in an adenoma surveillance program. Scand J Gastroenterol 1993;28:869-74.

4. Winawer SJ, Zauber AG, Ho MN, O'Brien MJ, Gottlieb LS, Sternberg SS, Waye JD, Schapiro M, Bond JH, Panish JF, et al. Prevention of colorectal cancer by colonoscopic polypectomy. The National Polyp Study Workgroup. N Engl J Med $1993 ; 329: 1977-81$

5. Johns LE, Houlston RS. A systematic review and meta-analysis of familial colorectal cancer risk. Am J Gastroenterol 2001;96:2992-3003.

6. Butterworth AS, Higgins JP, Pharoah P. Relative and absolute risk of colorectal cancer for individuals with a family history: a meta-analysis. Eur J Cancer 2006;42:216-27.

7. Pariente A, Milan C, Lafon J, Faivre J. Colonoscopic screening in first-degree relatives of patients with 'sporadic' colorectal cancer: a case-control study. The Association Nationale des Gastroenterologues des Hopitaux and Registre Bourguignon des Cancers Digestifs (INSERM CRI 9505). Gastroenterology $1998 ; 115: 7-12$

8. Lievre A, Milet J, Carayol J, Le Corre D, Milan C, Pariente A, Nalet B, Lafon J, Faivre J, Bonithon-Kopp C, Olschwang S, Bonaiti-Pellie C, Laurent-Puig P. Genetic polymorphisms of MMP1, MMP3 and MMP7 gene promoter and risk of colorectal adenoma. BMC Cancer 2006;6:270.

9. Cottet V, Pariente A, Nalet B, Lafon J, Milan C, Olschwang S, Faivre J, Bonaiti-Pellie C, Bonithon-Kopp C. Low compliance with colonoscopic screening in first-degree relatives of patients with large adenomas. Aliment Pharmacol Ther 2006;24:101-9.

10. Ahsan H, Neugut AI, Garbowski GC, Jacobson JS, Forde KA, Treat MR, Waye JD. Family history of colorectal adenomatous polyps and increased risk for colorectal cancer. Ann Intern Med 1998;128:900-5. 
11. Aitken JF, Bain CJ, Ward M, Siskind V, MacLennan R. Risk of colorectal adenomas in patients with a family history of colorectal cancer: some implications for screening programmes. Gut 1996;39:105-8.

12. Bazzoli F, Fossi S, Sottili S, Pozzato P, Zagari RM, Morelli MC, Taroni F, Roda E. The risk of adenomatous polyps in asymptomatic first-degree relatives of persons with colon cancer. Gastroenterology 1995;109:783-8.

13. Boutron MC, Faivre J, Quipourt V, Senesse P, Michiels C. Family history of colorectal tumours and implications for the adenoma-carcinoma sequence: a case control study. Gut 1995;37:830-4.

14. Lynch KL, Ahnen DJ, Byers T, Weiss DG, Lieberman DA. First-degree relatives of patients with advanced colorectal adenomas have an increased prevalence of colorectal cancer. Clin Gastroenterol Hepatol 2003;1:96-102.

15. Winawer SJ, Zauber AG, Gerdes H, O'Brien MJ, Gottlieb LS, Sternberg SS, Bond JH, Waye JD, Schapiro M, Panish JF, et al. Risk of colorectal cancer in the families of patients with adenomatous polyps. National Polyp Study Workgroup. N Engl J Med $1996 ; 334: 82-7$.

16. Rickert RR, Auerbach O, Garfinkel L, Hammond EC, Frasca JM. Adenomatous lesions of the large bowel: an autopsy survey. Cancer 1979;43:1847-57.

17. Vatn MH, Stalsberg H. The prevalence of polyps of the large intestine in Oslo: an autopsy study. Cancer 1982;49:819-25.

18. Endoscopie digestive basse: Indications en dehors du dépistage en population Agence Nationale d'Accréditation et d'Evaluation en Santé, 2004.

19. Smith RA, Cokkinides V, Eyre HJ. American Cancer Society guidelines for the early detection of cancer, 2004. CA Cancer J Clin 2004;54:41-52.

20. Winawer S, Fletcher R, Rex D, Bond J, Burt R, Ferrucci J, Ganiats T, Levin T, Woolf S, Johnson D, Kirk L, Litin S, Simmang C. Colorectal cancer screening and surveillance: clinical guidelines and rationale-Update based on new evidence. Gastroenterology 2003;124:544-60. 
Figure 1: Study population.

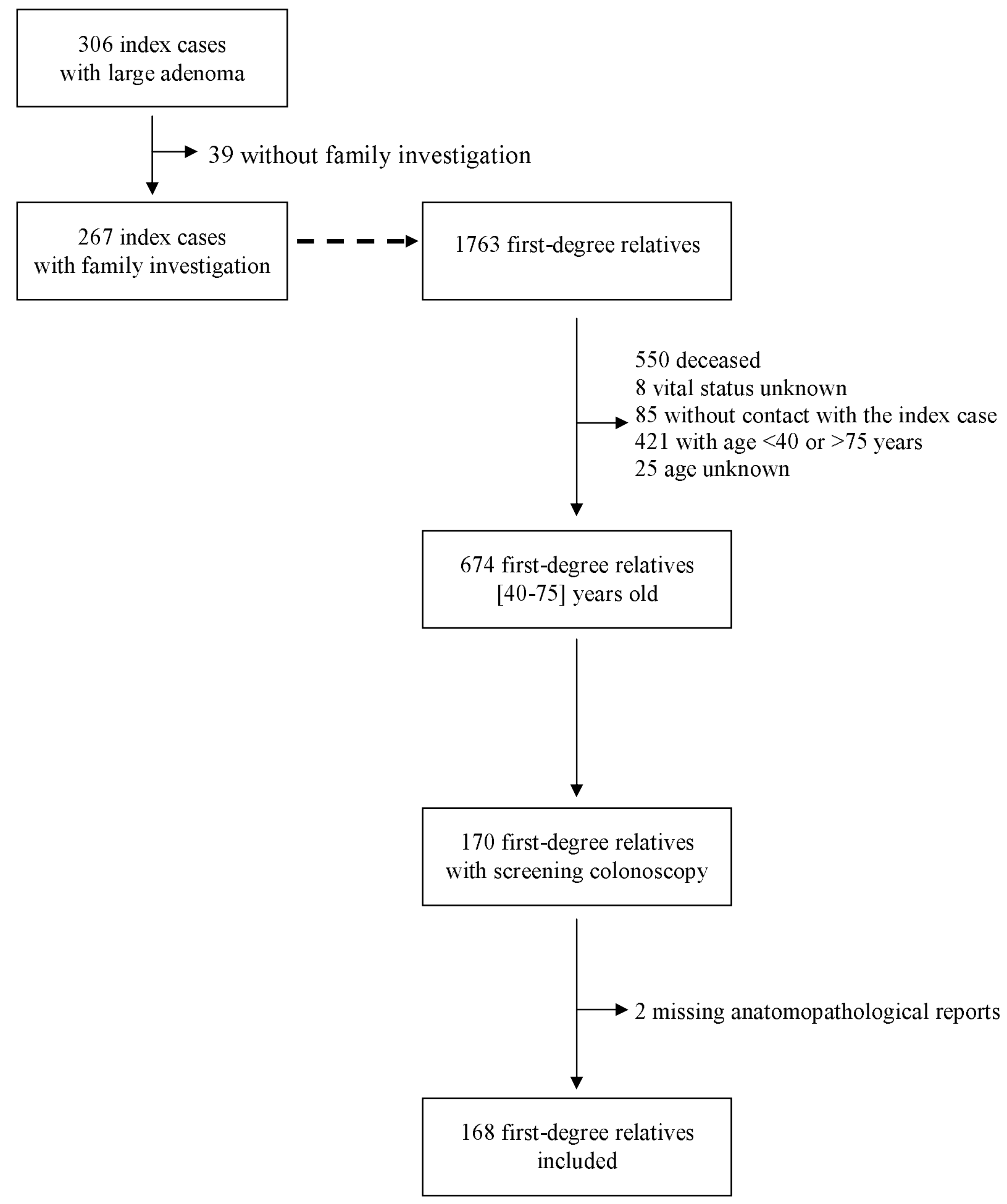


Table 1: Characteristics of first-degree relatives of patients with large adenomas (cases) and matched colonoscopic controls

\begin{tabular}{|c|c|c|}
\hline & Relatives & Matched controls \\
\hline & 168 & 307 \\
\hline \multicolumn{3}{|l|}{ Age (years) } \\
\hline Mean (SD) & $55.3 \quad(9.9)$ & $56.2 \quad(10.0)$ \\
\hline$<50-\mathrm{n}(\%)$ & $61 \quad(36.3)$ & 104 (33.9) \\
\hline $50-59-\mathrm{n}(\%)$ & $41 \quad(24.4)$ & $69 \quad(22.5)$ \\
\hline$\geq 60-n(\%)$ & $66 \quad(39.3)$ & 134 (43.6) \\
\hline
\end{tabular}

\section{Gender}

\begin{tabular}{|c|c|c|c|}
\hline Women - n $(\%)$ & & (55.4) & $168 \quad(54.7)$ \\
\hline Men $-\mathrm{n}(\%)$ & 75 & $(44.6)$ & $(45.3)$ \\
\hline
\end{tabular}

\section{Geographical area}

$\begin{array}{lllll}\text { Greater Paris area }-\mathrm{n}(\%) & 35 & (20.8) & 70 & (22.8) \\ \text { North-East }-\mathrm{n}(\%) & 30 & (17.9) & 60 & (19.5) \\ \text { South-West }-\mathrm{n}(\%) & 34 & (20.2) & 50 & (16.3) \\ \text { South-East }-\mathrm{n}(\%) & 34 & (20.2) & 57 & (18.6) \\ \text { Central France }-\mathrm{n}(\%) & 35 & (20.8) & 70 & (22.8)\end{array}$


Table 2: Risk of colorectal neoplasia among first-degree relatives of patients with large adenomas

\begin{tabular}{|c|c|c|c|c|c|c|c|}
\hline & \multicolumn{2}{|c|}{$\begin{array}{l}\text { Relatives } \\
\qquad N=168\end{array}$} & \multicolumn{2}{|c|}{$\begin{array}{c}\text { Matched } \\
\text { controls } \\
\mathbf{N}=\mathbf{3 0 7}\end{array}$} & \multicolumn{3}{|c|}{ Adjusted odds Ratios* } \\
\hline & $\mathbf{n}$ & $\%$ & $\mathbf{n}$ & $\%$ & OR & $95 \%$ CI & $\mathbf{p}$ \\
\hline No neoplasia & 130 & $(77.4)$ & 257 & $(83.7)$ & 1 & & \\
\hline Small adenomas & 22 & $(13.3)$ & 37 & $(12.0)$ & 1.21 & $0.68-2.15$ & 0.52 \\
\hline Cancers or large adenomas & 14 & $(8.4)$ & 13 & $(4.2)$ & 2.27 & $1.01-5.09$ & 0.046 \\
\hline cancers & 5 & $(3.0)$ & 3 & $(1.0)$ & 3.90 & $0.89-17.01$ & 0.07 \\
\hline large adenomas & 9 & $(5.4)$ & 10 & (3.3) & 1.82 & $0.71-4.69$ & 0.21 \\
\hline All neoplasia $\dagger$ & 38 & $(22.6)$ & 50 & $(16.3)$ & 1.56 & $0.96-2.53$ & 0.075 \\
\hline High-risk adenomas & 12 & $(7.2)$ & 13 & $(4.2)$ & 1.80 & $0.78-4.13$ & 0.17 \\
\hline Multiple adenomas & 5 & $(3.0)$ & 9 & $(2.9)$ & 1.10 & 0.35 .3 .44 & 0.87 \\
\hline Distal neoplasia $ף$ & 28 & $(16.8)$ & 35 & (11.4) & 1.66 & $0.95-2.91$ & 0.076 \\
\hline Proximal neoplasia $\mathbb{1}$ & 10 & $(6.0)$ & 19 & $(6.2)$ & 1.14 & $0.51-2.58$ & 0.75 \\
\hline
\end{tabular}

*: Adjustment for age, gender and geographical area of relatives and controls

$\uparrow: 2$ missing sizes for adenomas

¥: adenomas $\geq 10 \mathrm{~mm}$ and/or villous component and/or severe dysplasia or carcinoma in situ.

T: 1 missing location 


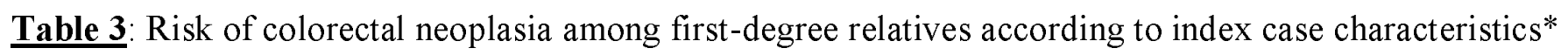

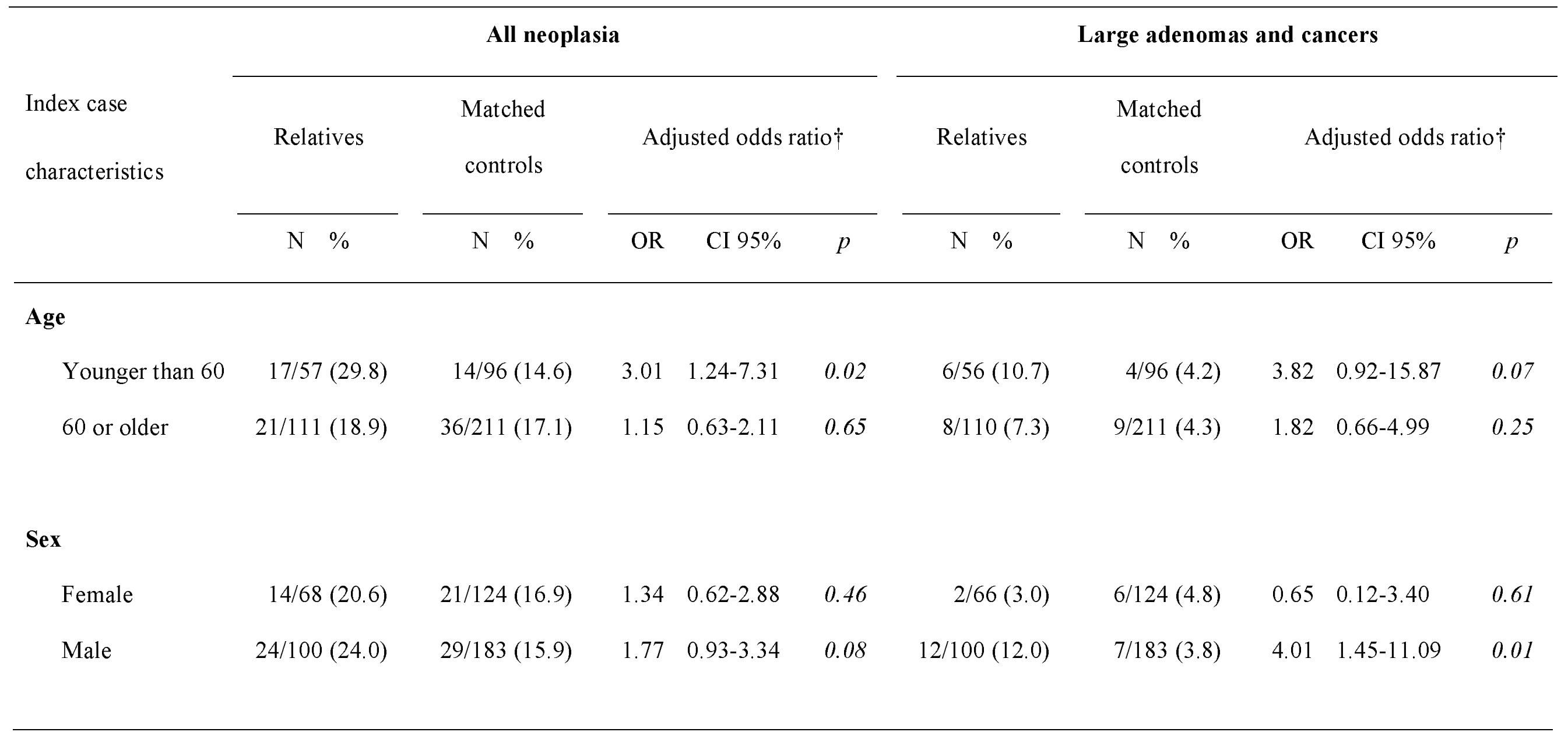




\section{$\underline{\text { Table } 3}$ (continued)}

\section{Adenoma location}

\begin{tabular}{|c|c|c|c|c|c|c|c|c|c|}
\hline distal colorectum & $31 / 138(22.5)$ & 40/259 (15.4) & 1.65 & $0.96-2.83$ & 0.07 & $13 / 136(9.6)$ & $9 / 259(3.5)$ & 3.14 & $1.27-7.73$ \\
\hline proximal colon & $8 / 37(21.6)$ & $11 / 62(17.7)$ & 1.29 & $0.45-3.71$ & 0.63 & $1 / 37(2.7)$ & $4 / 62(6.5)$ & 0.41 & $0.04-4.39$ \\
\hline
\end{tabular}

\section{Advanced}

adenomas :

$\begin{array}{lrrrrrrrrrrr}\text { yes } & 26 / 115(22.6) & 35 / 208(16.8) & 1.48 & 0.82-2.67 & 0.19 & 10 / 114(13.2) & 9 / 208(4.3) & 2.31 & 0.88-6.04 & 0.09 \\ \text { no } & 12 / 53(22.6) & 15 / 99(15.2) & 1.74 & 0.72-4.18 & 0.22 & 7 / 52(13.5) & 11 / 99(11.1) & 2.19 & 0.48-10.03 & 0.31\end{array}$

*: Logistic regression stratified by index case characteristics

$\uparrow$ : Adjustment for age, gender and geographical area of relatives and controls

\$: Adenomas with villous component and/or severe dysplasia or carcinoma in situ 